\title{
Nurses and guideline for interrupting or not initiating CPR: An exploratory survey
}

\author{
Claudia Agnoletto*1, Fancesco Gastaldo ${ }^{2}$, Simonetta Padrin ${ }^{1}$ \\ ${ }^{1}$ University of Padua/Monselice, Italy \\ ${ }^{2}$ North Italian Hospital, Italy
}

Received: February 13, 2019

Accepted: June 24, 2019

Online Published: August 13, 2019

DOI: $10.5430 / \mathrm{cns} . v 7 \mathrm{n} 4 \mathrm{p} 13$

URL: https://doi.org/10.5430/cns.v7n4p13

\begin{abstract}
Objective: An area that still causes difficulties and a sense of inadequacy in healthcare providers is related to Do Not Attempt Resuscitation decision (DNAR). The aim of the study is to investigate knowledge, opinions and behaviors of nurses about DNAR in order to plan appropriate improvement interventions.

Methods: An anonymous questionnaire was administered to 207 nurses belonging to four Medicine Departments and to four Intensive Care areas. The questionnaire, which consists of 29 items, collects some information related to work experience and investigates opinions and behaviors of nurses about DNAR decision.

Results: $55 \%$ of the nurses in the sample say they do not know the meaning of the acronym DNAR. It was noted a statistically significant association both between training and knowledge of DNAR ( $p$-value $=.038$ ) and between years of work and knowledge of the acronym $(p$-value $=.004)$. There was also a statistically significant difference between knowledge of the acronym and some opinions and behaviors of nurses, including the importance of informing the patient about DNAR decision $(p$-value $=.028)$.

Conclusions: The study shows that the sample investigated, regardless of the work area of afference, does not know DNAR decision adequately. The lack of knowledge influences opinions and attitudes of nurses in relation to DNAR decision, constituting a barrier for an appropriate management of the patient. The need for more training on the topic and the formulation of clear protocols on DNAR decision emerges.
\end{abstract}

Key Words: Do Not Attempt Resuscitation decision, Nurses, Attitudes, Advance statements of treatment

\section{INTRODUCTION}

Patient care has always involved ethical issues and required the possession of high moral principles by the healthcare providers. No other era has faced moral issues such as those we are facing today dictated by the change linked to the emancipation of patient, the event of new medical technologies, the access to health services to every citizen. ${ }^{[1]}$

With the scientific knowledge progress and the consequent increase in the chances of survival even as a result of serious pathologies, the need to be able to oppose any clinical obstinacy made its way into public opinion, privileging the concept of therapeutic desistance.

In Italy, the recent law n. 219 of the $22^{\text {nd }}$ of December $2017^{[2]}$ on the Advance Statements of Treatment makes possible to concretize a sort of mediation between professional autonomy and patient's decision-making autonomy, favouring the reacquisition of the person's full power over itself.

As highlighted in article 2, the physician must abstain from the organization of medical treatments if these result to be

*Correspondence: Claudia Agnoletto; Email: claudia.agnoletto96@gmail.com; Address: University of Padua/Monselice, Italy. 
unnecessary or disproportionate.

Article 4 deals in detail with the "Share care planning", describing the possibility for people able to understand and take action, to express their intentions with respect to medical treatment and to identify a "trustee" who takes their place.

The approval of this law has encouraged the debate on various aspects of clinical practice that imply ethical issues which are still unsolved. An area that still causes difficulties and a sense of inadequacy in healthcare providers is related to Do Not Attempt Resuscitation decision (DNAR), that is the decision to not perform resuscitation maneuvers in some types of patients.

Although the first references date back to the 70 s in the United States, today in many countries there is a significant variability in the formulation, registration and application of it. ${ }^{[3]}$

Within the European Union there are important differences both in the approach to cardiopulmonary resuscitation and the topic of the end of life, and for this reason the European Resuscitation Council ${ }^{[4]}$ has drawn up guidelines to homogenize them.

According to the latest European Resuscitation Council guidelines, ${ }^{[4]}$ cardiopulmonary resuscitation should be avoided or suspended in cases where operator safety is not guaranteed, when it is futile, when there is valid Advance Directive, when death is irreversible and also in cases when resuscitation maneuvers are in contrast with the patient's values.

As reported in the Ethics section of the 2015 Guidelines of the European Resuscitation Council, ${ }^{[4]}$ the care relation, traditionally centered on the physician and on the principle of beneficence, has moved over the years towards the principle of autonomy of the person. In a patient-centered view of care, the values of the person are crucial in the decision about the suspension or continuation of treatments in intensive care. In the absence of Advance Statements of Treatment, the family (or in any case the closest people to the patient) become an important source of information about the person's will. In this case it becomes fundamental for the physician to know how to discern between the desires of the family and the desires of the person. ${ }^{[5]}$

Deepening the DNAR order, it can be seen how nurses support the need for greater clarity and sharing of it, requiring that the communication of this decision is provided in writing. ${ }^{5]}$ The verbal transmission of the DNAR order, and therefore its informality, in fact, causes in nurses the fear of possible legal re-runs, in particular from the patient's family, in the event that this order is applied in clinical practice. ${ }^{[6]}$

The responsibility in the DNAR decision is attributed, by most nurses, only to physicians, although this decision should be agreed with other physicians, ethics committees and nurses. Both physicians and nurses, in fact, tend to claim that this decision should not be taken by the latter and that, even in the event of disagreement with the DNAR order, nurses should adhere to this order. ${ }^{[7]}$ Even if the decision-making responsibility is attributed to the physicians, part of the nursing community desires to be more involved in DNAR decisions. In particular, nurses wish to be consulted, like physicians, as holders of a unique relationship that binds them to patients. ${ }^{[8]}$ Despite this, only a small part of nurses reports that they were actually consulted. ${ }^{[9]}$

Regarding the consent to the DNAR order, nurses claim the need to involve patient and family members in the decisionmaking process and the necessity to provide them all the informations relating the resuscitation policies from the moment of the admission in the ward. ${ }^{[10]}$ The responsibility to inform and receive the patient's consent for the DNAR order is attributed only to physicians. ${ }^{[7]}$

\section{METHODS}

The survey was conducted in eight wards, four in Medicine Departments and four in Intensive Care areas of three Hospitals in the North of Italy. The applied sampling method is based on convenience and in compliance with the following criteria:

\section{Inclusion criteria}

Nurses belonging to two Intensive Care Units, four Medicine Departments, two Emergency Departments services of 3 Hospitals.

\section{Exclusion criteria}

- Nurses who do not provide direct assistance at the respective Operating Units, including the Nursing Coordinators;

- Nurses belonging to one of the three Intensive Care Units present in the Company as instructors of BLSD courses in which training and sensitization of DNAR decision is foreseen.

Regarding the power analysis in reference to sample size, the minimum rate of adherence to the questionnaire for each ward is $80 \%$.

The questionnaires were administered personally to the nurses in each Operating Unit, with informed consent and guaranteeing anonymity. The support, if required, consisted in the clarification of what is reported in the text of the ques- 
tions.

After obtaining the authorization for data collection, of each ward was set up a meeting with the Nursing Coordinators of each ward, aimed at illustrating the instrument. Data collection was conducted:

- In the months of May and June 2018 at the two Medicine wards A1 and A2 and Emergency room B1 of the first Hospital;

- In August 2018 at the Medicine wards A3, Emergency room B2 and Intensive Care Unit C1 of the second Hospital;

- In September 2018 at the Medicine wards A4 and Intensive Care Unit C2 of the third Hospital.

The questionnaires were administered personally to the nurses in each ward, prior consent and guaranteeing anonymity. The support consisted, if requested, exclusively, in the clarification of what is reported in the text of the question, paying attention to assume a neutral attitude. At the end of each compilation the questionnaire was inserted in the appropriate folder relative to the ward to which it belonged

At the end of each compilation, the questionnaire has been put in the appropriate folder relative to the ward it belongs.

From the research in the literature, the questionnaire was selected from 'Nurses' attitudes towards Do Not Attempt Resuscitation orders" study. ${ }^{[3]}$

Subsequently, after having received the consent of the author to translate his study in Italian, the translation has been certified.

Subsequently, the questionnaire was administered, with the consent and guaranteeing anonymity, to six experienced nurses, three belonging to the medical area and three to the critical area, to perform linguistic and cultural validation.

Following this procedure, some changes were made to the questionnaire.

Table 1. Sample master data

\begin{tabular}{lllll}
\hline Population & Number of responses & Age range & Total working years & Years of working in the current ward \\
\hline Medicine A1 & $24(82.7 \%)$ & $40-50(46 \%)$ & $16.7 \pm 10.8^{*}$ range $(1.5-35)$ & $6.8 \pm 7.7$ range $(0-25)$ \\
Medicine A2 & $21(84 \%)$ & $30-39(38 \%)$ & $14.1 \pm 9.6^{*}$ range $(2.5-30)$ & $7.9 \pm 7.8$ range $(0.3-24)$ \\
EmergencyB1 & $56(82.3 \%)$ & $40-50(43 \%)$ & $17.3 \pm 10.8^{*}$ range $(1.5-39)$ & $10 \pm 8.79$ range $(0-38)$ \\
Medicine A3 & $17(94.4 \%)$ & $50-50(64.5 \%)$ & $21.2 \pm 11^{*}$ range $(2-41)$ & $12.1 \pm 10.2$ range $(0.5-35)$ \\
ICU C1 & $21(80.7 \%)$ & $40-50(43 \%)$ & $19.9 \pm 11.2^{*}$ range $(3-40)$ & $12.4 \pm 12.3$ range $(0.1-40)$ \\
Emergency B2 & $28(84.8 \%)$ & $40-50(50 \%)$ & $14.6 \pm 10.6^{*}$ range $(2-38)$ & $16.7 \pm 10.8$ range $(0-27)$ \\
Medicine A4 & $12(80 \%)$ & $>50(42 \%)$ & $17.9 \pm 16.1^{*}$ range $(1-39)$ & $12.2 \pm 13.2$ range $(0.25-35)$ \\
ICU C2 & $28(82.3 \%)$ & $40-50(39.5 \%)$ & $18.5 \pm 10.3^{*}$ range $(2-32)$ & $12.3 \pm 7.6$ range $(0.4-29)$ \\
\hline
\end{tabular}

In order to ensure the reliability of the data collected, the choice was to be present during the compilation of the questionnaires, guaranteeing a quiet environment without any possible interruptions.

Anonymity and correct separation of questionnaires for each ward was ensured, including them in individual and labeled folders. The collected data were processed using Excel $\mathrm{R}$ calculation program and the descriptive statistical analysis tools: absolute, relative and percentage frequency; position indexes such as mean with standard deviation, median and range.

For the differences in response to the questionnaire between the cohorts and any associations between some investigated variables, the Chi Quadro test and the Fisher exact test were used, in the case of expected variables less than 5. A statistical significance level $\leq 0.05$ was accepted.

\section{RESUlts}

The sample, whose characteristics are shown in Table 1, consists of 207 nurses, and among them 133 belong to the critical area (2 Emergency Departments Units and 2 Intensive Care Units). The sample is made up for the most part (43\%) of professionals belonging to the age group between 40 and 50 years; the percentage of nurses with less than 29 years is in fact represented only by $16 \%$.

The average age of the sample is also confirmed by the total number of years of work experience, the median of which is equal to 20. From the analyzed data, it is also highlighted that newly recruited nurses constitute a small percentage of the sample; in fact, the median relating to the years worked at the current Operating Unit is equal to 8.

$89 \%$ of nurses also have a basic education, while those who have achieved the 1 st and 2 nd specialized masters are a small percentage of the sample.

Note. ${ }^{*}$ media $\pm S D$ 
Was also investigated nurses' knowledge of the meaning of the acronym DNAR. 195 nurses, belonging to the eight wards included in the sample, answered the question. The analysis showed that more than a half of the nurses reported to not know the meaning of the acronym; the answer "no" has in fact an absolute frequency equal to 107 and a percentage frequency of $55 \%$.

As shown in Figure 1, there are three wards in which the answer "yes" has a higher percentage frequency than "no" and belong to the same Hospital (Medicine Department A1 = "yes" 74\%, Medicine Department A2 = "yes" 59\%, Emergency Department B1 = "yes" 61\%).

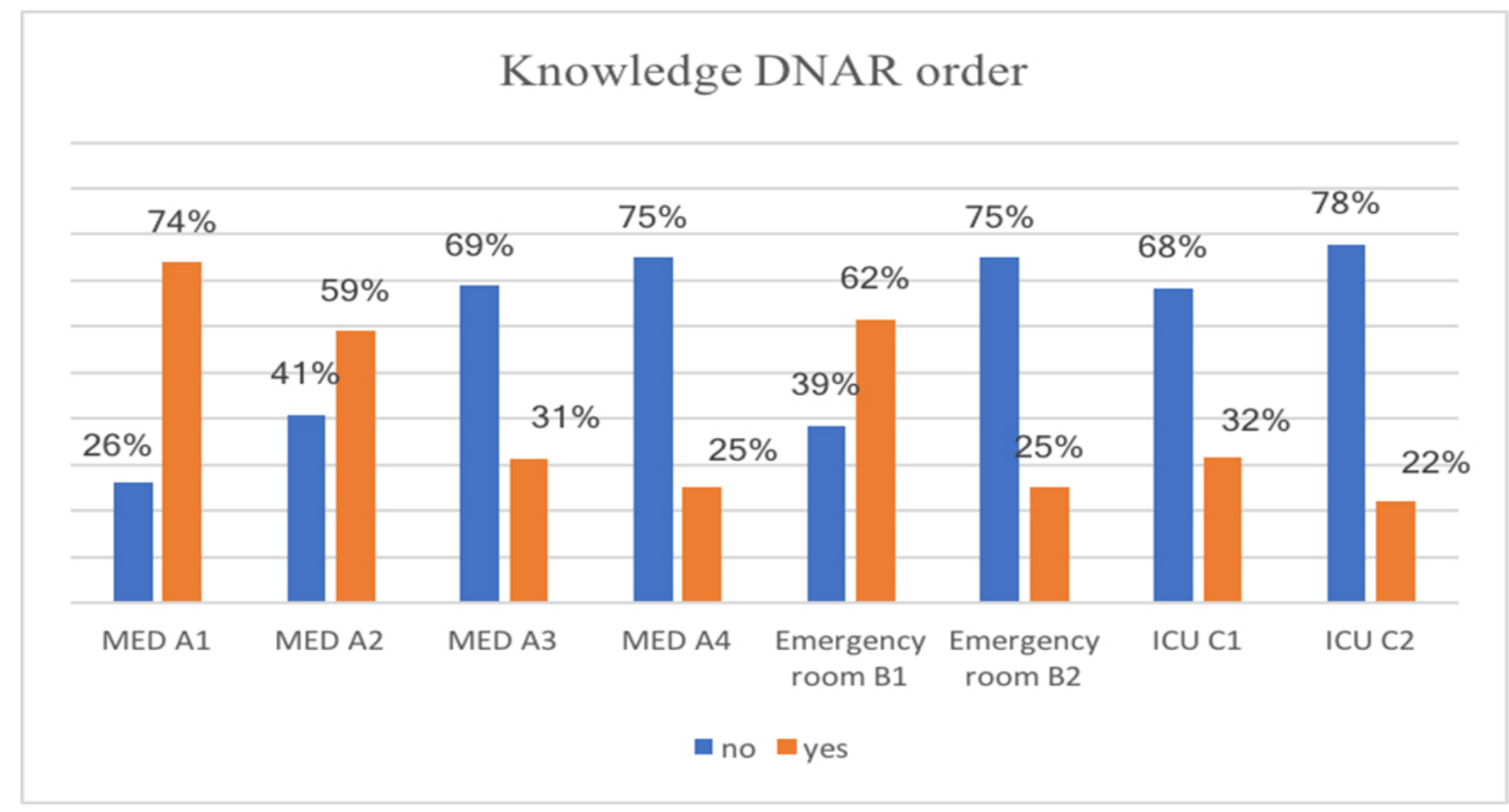

Figure 1. Knowledge frequences of DNAR

We also compared the knowledge of DNAR decision of nurses of critical area with ones of the medical area, considering all the wards belonging to the three Hospitals. It has been observed that nurses of the medical area have a greater knowledge of DNAR decision (54\%) than those belonging to the critical area $(40 \%)$.

Training data have been analyzed: the basic training, including Bachelor's Degree, Regional School and Regional School with an integrative year, and the post-basic training which involves the Master of science, 1st and 2nd level specialized master, was distinguished.

Out of a total of 206 responses, $89 \%$ of nurses reported to have basic training.

The possible association between the knowledge of DNAR decision and the qualification has been investigated.

The application of the Chi-Square test showed that there is a statistically significant difference between the two variables $\left[\chi^{2}(\mathrm{gl} \mathrm{1})=4.313, p=.038\right]$, so the formation affects the knowledge of DNAR decision.
Data relating to the total years of work have been analyzed. Based on the median, which is equal to 20 , the sample was divided into two groups: those who have a work experience of less than 20 years and those who report a total of working years greater or equal to 20 .

206 nurses answered the question, and $52 \%$ of them stated that they had work experience of 20 years or more.

The possible association between knowledge of DNAR decision and total years of work experience was also investigated. Chi-Square test demonstrated a statistically significant difference between the variables considered $\left[\chi^{2}(\mathrm{gl} 1)=8.088, p=\right.$ $.004]$, so the years of work experience affect the knowledge of the meaning of the acronym.

It was also investigated whether the knowledge of DNAR affects opinions and behaviors of nurses.

In particular, the item explores the behavior of nurses in reanimating the patient in the absence of DNAR decision.

Out of a total of 204 responses, $85 \%$ of nurses report to reanimate the patient in the absence of a DNAR decision, while 
$3 \%$ say they do not resuscitate and $4 \%$ agree with the doctor.

The Chi-Square test was applied: it demonstrated statistical significance only in the association between the knowledge of DNAR and the "Do resuscitate" answer $\left[\chi^{2}(\mathrm{gl} \mathrm{1})=4,787\right.$, $p=.029]$.

Nurses' opinion about informing patients on DNAR decision was studied.

Total answers are 206 and $61 \%$ of nurses indicates the answer "always".

Subsequently the Chi-Square test was applied and it showed a statistically significant difference between the knowledge of DNAR and the answers "always" $\left[\chi^{2}(\mathrm{gl} \mathrm{1})=4.801\right.$, $p=.028]$ and "sometimes" $\left[\chi^{2}(\mathrm{gl} 1)=5.880, p=.015\right]$ related to the duty of informing the patient.

Subsequently, the item that investigates the opinions of nurses on who has the duty to inform the patient about DNAR decision has been analyzed.

As shown in Figure 2, the majority of nurses $(61 \%)$ answered that is the physician who has to inform the patient about DNAR decision.

$12 \%$ believe that the patient should be informed by both the physician and the family. The nurse, as a person responsible of informing the patient, appears in two ways: in association with the physician $(9.5 \%)$ and together with the physician and the family (8\%).

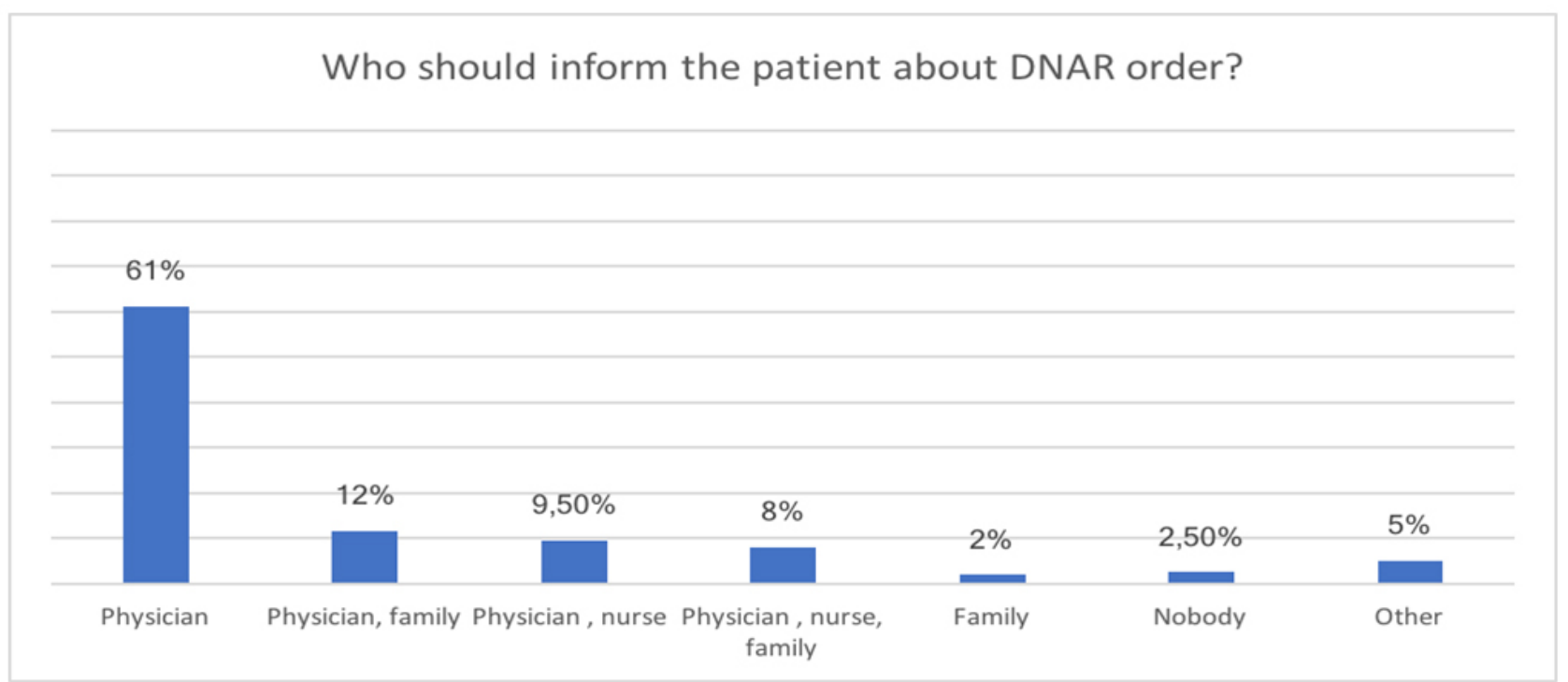

Figure 2. Frequences about who has to inform patient on DNAR

The items investigate which types of patients, according to their work experience, nurses can consider candidates for DNAR decision.

In particular, the Chi-Square test highlighted the statistical association between knowledge and predisposition to consider the following patients as possible candidates for DNAR:

- terminal patients, in particular related to the answer "sometimes" $\left[\chi^{2}(\mathrm{gl} \mathrm{1})=4.674, p=.031\right]$;

- patients in the nursing home, related referring to the answer "never" $\left[\chi^{2}(\mathrm{gl} \mathrm{1})=6.886, p=.009\right]$;

- patients older than 65 years, in particular concerning related to the answer "never" $\left[\chi^{2}(\mathrm{gl} 1)=5.727\right.$, $p=.017]$.

Published by Sciedu Press

\section{DisCUSSION}

Despite DNAR decision is fully part of the advance directive, it isn't mentionated in the recent law n. 219 of the $22 \mathrm{nd}$ of December 2017, ${ }^{[2]}$ that recognizes the principle of therapeutic self-determination and the right to live all phases of one's life without undergoing medical treatment contrary to one's will. ${ }^{[12]}$

In fact $55 \%$ of nurses who answered the questionnaire said they do not know the meaning of the acronym DNAR, and $83 \%$ said they were satisfied with their resuscitation skills.

The question that arises then is: "Does cardiopulmonary resuscitation count only on technical aspects or also on possible ethical implications whose practice entails?" 
Table 2. Results

\begin{tabular}{|c|c|}
\hline Question text & Responses \\
\hline What percentage of cardiac arrests, that you have attended, has been successful? & $\chi^{2}=25(S D=0.27), \quad$ Median $=10$ \\
\hline \multirow{2}{*}{ Are you happy with your resuscitation skills? } & a) Yes n. $167(83 \%)$ \\
\hline & b) No n. 35 (17\%) \\
\hline Are you aware of the meaning of the acronym DNAR? & a) Yes n. $88(45 \%)$ \\
\hline If so, on what occasion did you come to know about it? & b) No n. $107(55 \%)$ \\
\hline \multirow{3}{*}{ Are you aware of a written hospital policy on DNAR decisions? } & a) Yes n. $22(11 \%)$ \\
\hline & b) No n. $182(89 \%)$ \\
\hline & c) Other n. $0(0 \%)$ \\
\hline \multirow{3}{*}{ If resuscitation status has NOT been decided for a patient, what do you do? } & a) Do Resuscitate n. 174 (85\%) \\
\hline & b) Do Not Resuscitate n. 7 (3.5\%) \\
\hline & c) Other n. $23(11.5 \%)$ \\
\hline \multirow{6}{*}{ How do you know which patients are DNAR? (more than one response possible) } & a) Written in medical notes n. $113(58 \%)$ \\
\hline & b) Written in nursing notes n. $68(35 \%)$ \\
\hline & c) Written on patient board n. $10(5 \%)$ \\
\hline & d) Verbal handover from nurses n. $41(21 \%)$ \\
\hline & e) Don’t know n. 44 (23\%) \\
\hline & f) Other n. $28(14 \%)$ \\
\hline \multirow{9}{*}{ Who should decide on DNAR status? (more than one response possible) } & a) Medical director n. $32(16 \%)$ \\
\hline & b) Physician n. 75 (37\%) \\
\hline & c) Medical expert n. $68(34 \%)$ \\
\hline & d) Intern n. $0(0 \%)$ \\
\hline & e) Nursing coordinator $n .2(1 \%)$ \\
\hline & f) Nurse n. $6(3 \%)$ \\
\hline & g) Patient n. $129(63.5 \%)$ \\
\hline & h) Family n. $108(53 \%)$ \\
\hline & i) Other n. $13(6 \%)$ \\
\hline \multirow{4}{*}{ Should the patient be informed? } & a) Always n. $125(61 \%)$ \\
\hline & b) Sometimes n. 47 (23\%) \\
\hline & c) Never n. $11(5 \%)$ \\
\hline & d) Other n. $23(11 \%)$ \\
\hline \multirow{5}{*}{ If yes, who should inform the patient? (more than one response possible) } & a) Physician n. 179 (90\%) \\
\hline & b) Nurse n. $35(18 \%)$ \\
\hline & c) Family n. 43 (22\%) \\
\hline & d) Nobody n. $5(2.5 \%)$ \\
\hline & e) Other n. $10(5 \%)$ \\
\hline \multirow{6}{*}{ Based on your experience, what format are most DNAR decisions: } & a) Written n. $42(21 \%)$ \\
\hline & b) Verbal n. $43(21 \%)$ \\
\hline & c) Both written and verbal n. $42(21 \%)$ \\
\hline & d) Neither n. $0(0 \%)$ \\
\hline & e) Never met n. $70(34 \%)$ \\
\hline & f) Other n. $6(3 \%)$ \\
\hline \multirow{5}{*}{ If present, do you think that DNAR decisions are clear? } & a) Always n. 20 (10\%) \\
\hline & b) Sometimes n. $80(40 \%)$ \\
\hline & c) Never n. $20(10 \%)$ \\
\hline & d) Never met n.72 (36\%) \\
\hline & e) Other n. $9(4 \%)$ \\
\hline \multirow{4}{*}{ According to your experience, do physicians discuss DNAR decisions with you? } & a) Always n. 5 (3\%) \\
\hline & b) Sometimes n. $69(34 \%)$ \\
\hline & c) Never n. 107 (53\%) \\
\hline & d) Other n. $20(10 \%)$ \\
\hline \multirow{4}{*}{ In your experience, do physicians make the right DNAR decisions? } & a) Always n. 34 (17\%) \\
\hline & b) Sometimes n. $117(59 \%)$ \\
\hline & c) Never n. $9(4.5 \%)$ \\
\hline & d) Other n. $22(19.5 \%)$ \\
\hline \multirow{8}{*}{$\begin{array}{l}\text { According to your experience, which of the following treatments is appropriate in a } \\
\text { patient who is not for resuscitation (more than one response possible): }\end{array}$} & a) Oxygen n. 127 (65\%) \\
\hline & b) IV fluids n. $122(62 \%)$ \\
\hline & c) Antibiotics n. 30 (15\%) \\
\hline & d) NG feeding n. $44(22 \%)$ \\
\hline & e) Intubation n. $13(7 \%)$ \\
\hline & f) Defibrillation n. $13(7 \%)$ \\
\hline & g) None of these n. $26(13 \%)$ \\
\hline & h) Other n. $28(14 \%)$ \\
\hline \multirow{4}{*}{$\begin{array}{l}\text { From your professional experience, do you think DNAR decisions are effectively } \\
\text { used? }\end{array}$} & a) Always n. 21 (10.5\%) \\
\hline & b) Sometimes n. $105(52 \%)$ \\
\hline & c) Never n. $28(14 \%)$ \\
\hline & d) Other n. $47(23.5 \%)$ \\
\hline \multirow{2}{*}{ Do you think you need more training? } & a) Yes n. $189(95 \%)$ \\
\hline & b) No n. $10(5 \%)$ \\
\hline
\end{tabular}


The three Operative Units (two Medicine Departments and Emergency Department) in which the percentage of nurses who know DNAR is greater than those who do not know, belong to the same hospital presidium. This can be justified by the fact that in this hospital presidium there is a training plan in place, within the BLSD course, that makes possible to raise awareness among health professionals about the ethical aspects of cardiopulmonary resuscitation including DNAR decision.

In Goniewicz et al.'s study, ${ }^{[5]}$ it is possible to note how the majority $(80.5 \%)$ of nurses, belonging to the critical area, claims to know the acronym DNAR, but $75.6 \%$ say they do not know when it can be applied.

The reduced knowledge of the acronym is accompanied by the reduced involvement of nurses in DNAR decisions by medical personnel.

In fact, it can be seen that most nurses (53\%) say they are never involved. This aspect has also been found in "Critical Care Nurses' Perceptions of DNR Status" ${ }^{[14]}$ where $63 \%$ of nurses of critical area say they rarely participate. Furthermore in Canada, Jordan also reported little involvement of critical area nurses in DNAR decisions, only $21 \%$ said they were consulted in drafting these decisions. ${ }^{[10]}$

Nurses are not only not involved, but at the question "Who should decide on DNAR decision?" (With the possibility to choose more professionals in decision making) only $3 \%$ answered "nurse", reputed this as part of the team that evaluates the decision; this can be read as a distrust by the nurses themselves and could be an obstacle for the change.

These data are in accordance with what was reported by O'Hanlon $^{[3]}$ in which only $22 \%$ of nurses say they must be involved in such decisions. Fallahi et al. ${ }^{[7]}$ show that both the medical and nursing staff claim that DNAR decision should not be taken by the nurses and that even in case of disagreement with that decision, they have to stick with what was decided.

The analysis shows that $67.5 \%$ of nurses say they have never been in disagreement with a DNAR decision, and indeed, during the compilation of the questionnaire some nurses have reported, to be more often opposed to the non-application of DNAR than to his practice.

One of the open-answer question is in fact related to the behavior in case of disagreement with DNAR decision. Most nurses report to follow the same decision $(31 \%)$ or to discuss it as a team $(37.5 \%)$. However, the curiousness is that $4 \%$ of nurses said to reanimate the patient despite DNAR decision.

This attitude can not only go against the will and decision- making autonomy of the patient, sanctioned by the new law n. 219 of 22 nd December $2017,{ }^{[2]}$ but could also undermine respect referring to the principle of proportionality of care.

Since nurses tend to give decision-making responsibility on DNAR decision to the doctor (87\%) and are rarely involved in such decisions, they believe that the physician should also be responsible to inform the patient about DNAR decision $(90 \%)$, in accordance with what was reported by O'Hanlon et al. ${ }^{[3]}$

The majority of nurses $(61 \%)$ believe that the patient should always be informed about DNAR decision, as reported in Naess. ${ }^{[15]}$ The principle key of the law ${ }^{[2]}$ is that every person is the subject of care and has the right - if he or she wants to be properly informed and to guide decisions, accepting or rejecting responsibly any therapeutic proposal that does not conform to his/her project of life: it is therefore the person with his personal history the center of care and the reference point of every decision. ${ }^{[6]}$

The nurses of the sample of this study have a more positive attitude $(75 \%)$, compared to the study of O'Hanlon et al., ${ }^{[3]}$ also in regularly consulting patients about their wishes.

A similarity with this last study can be found by analyzing the responses to the items related to the types of patients that can be considered possible candidates for the decision to not resuscitate. In particular, in both analyses, it was found that most nurses occasionally consider "DNAR" the following patients: terminal, oncology, over sixty-five and guests in nursing home.

Furthermore is investigated the most frequent form in which DNAR decision is presented and the percentage frequencies detected are overlapping with regard to the "written", "verbal" and "both" answers (21\%), while $34 \%$ claims to have never met a DNAR decision. From the revised literature, instead, it emerges that the majority of nurses (81\%), say that in clinical practice DNAR decision is transmitted in written form, ${ }^{[16]}$ as reported in O'Hanlon et al. ${ }^{[3]}$

In the present study the percentage response frequencies related to the communication modalities of DNAR decision underlines the lack of a shared company procedure. This could also explain why $40 \%$ of nurses say that DNAR decision is only occasionally clear. During the compilation of the questionnaires some nurses also reported that often DNAR decision is not clear due to lack of sharing and cohesion also within the medical team cause this decision is often not supported by all the doctors.

The literature also shows the absence of a statistically significant association between training, age and years of work 
experience with the attitudes of nurses towards DNAR decision. ${ }^{[15]}$

In the present study it was demonstrated the statistically significant association between knowledge of DNAR and formation $\left[\chi^{2}(\mathrm{gl} \mathrm{1})=4.313, p=.038\right]$ and between the acronym's knowledge and years of work experience $\left[\chi^{2}(\mathrm{gl} 1)=8.088\right.$, $p=.004]$. In addition, the statistical association between the acronym knowledge and some nurses attitudes was detected, including also informing the patient about DNAR decision $\left[\chi^{2}(\mathrm{gl} 1)=4.801, p=.028\right]$.

One of the last items in the questionnaire assesses the training needs of nursing staff on DNAR decision. As highlighted earlier, $95 \%$ of nurses affirm the need for more training; this percentage is higher than the one reported in an other study, ${ }^{[3]}$ in which a considerable part of the nurses $(24 \%)$ reported that they did not need it.

The analysis of the results indicates a reduced knowledge of DNAR decision that inevitably affects the appropriateness of application of it by the nurses. The need for more training on the argument is evident especially from the last question analyzed and from the answers given to each item.

\subsection{Limits of the study}

The limits of the present study are the following:

- The sampling method is based on convenience;

- The sample, constitutes only a small part of the nurses who work in the three different hospitals;

- The possible misinterpretation of the text of the question by the individual professional, attenuated by the constant presence of the administrator;

- The possible presence of distractive factors during the completion of the questionnaire;

- Religious beliefs that may affect the attitude of nurses towards DNAR decision have not been investigated.

\section{Conclusions}

The dignity of dying is the true therapeutic goal in terminally ill patient, a phase that consists in a progressive and unstoppable decline in physiological functions. ${ }^{[17]}$

Keeping this in mind, the need for advance care planning emerges as a continuous process in which patients, their families and health professionals reflect on the patient's goals, values and beliefs and discuss current and future medical care. ${ }^{[18]}$
Some authors have suggested that early care planning also reduces moral distress among health care professionals who take care of the person. ${ }^{[19]}$

DNAR decision is fully part of the advance directive: the present study highlighted a reduced knowledge of DNAR decision by nurses and the lack of knowledge that affects opinions and attitudes of the professionals towards DNAR decision, constituting a barrier for proper patient care.

Therefore, the need for greater awareness and training on the issue emerges as well as the drafting of clear protocols on DNAR decision, so, for increasing the training, it is proposed to:

- Insert the theme of DNAR decision among the topics of the BLSD course;

- Organize moments of awareness on the topic open to all the staff with the involvement of the bioethics committee;

- Solicit the discussion of the team in the individual wards with themed discussions regarding the clinical cases that raise the highest moral distress.

It is also proposed the drafting of a shared DNAR decision protocol, legally valid and ethically appropriate, to facilitate decisions to implement DNAR decision and homogenize behaviors.

With regard to the implication for research, it is necessary:

- To extend the survey to other settings and not just to hospitals;

- To promote in-depth studies with techniques such as focus groups on specific aspects, aimed, for example, at:

a) evaluating the influence of values and/or religious beliefs on the attitude towards DNAR decision;

b) investigating knowledge and attitudes towards the advance directive in general;

c) deepening the specific aspects of communication related to the end of life issues within the team.

\section{ACKNOWLEDGEMENTS}

We would like to thank all the nurses who made themselves available for completing the questionnaire and collecting data.

\section{CONFLICTS OF INTEREST DisClosure}

The authors declare they have no conflicts of interest. 


\section{REFERENCES}

[1] Viafora C, Gaiani A. A lezione di Bioetica. Temi e strumenti. Milano: Franco Angeli Editore. 2015.

[2] Presidente della Repubblica Italiana. Legge 22 dicembre, n 219 Norme in materia di consenso informato e di disposizioni anticipate di trattamento. Gazzetta Ufficiale della Repubblica Italiana. 2017(12): $1-4$.

[3] O'Hanlon S, O'Connor M, Peters C, et al. Nurses' attitudes towards Do Not Attempt Resuscitation orders. Clinical Nursing Studies. 2013; 1(1): 43-50. https : //doi.org/10.5430/cns.v1n1p43

[4] Bossaert LL, Perkins GD, Askitopoulou H, et al. Sezione 11. Etica della Rianimazione Cardiopolmonare e delle decisioni di fine vita. Linee guida European Resuscitation Council. 2015; 302-312. PMid: 26477419. https://doi.org/10.1016/j.resuscitat ion. 2015.07.033

[5] Goniewicz M, Rzonca P, Klukow J, et al. DNR declaration- emergency medical system nurses' opinions. Central European Journal of Medicine. 2013; 8(1): 69-74. https://doi.org/10.2478/s115 36-012-0092-y

[6] Abdolghader A, Nabavi FH, Ebadi A, et al. Do-not-resuscitate Order: The Experiences of Iranian Cardiopulmonary Resuscitation Team Members. Indian Journal of Palliative Care. 2017; 23: 88-92. PMid: 28216869. https://doi.org/10.4103/0973-1075.197946

[7] Fallahi M, Mahdavikian S, Abdi A, et al. Nurses and physicians' viewpoints about decision making of do not attempt resuscitation (DNAR). Multidisciplinary Respiratory Medicine. 2018; 13(20): 1-7. PMid: 30013772. https://doi.org/10.1186/s40248-018-0133-8

[8] Jacqueline J. Do not attempt resuscitation decisions: the nursing role. British Journal of Nursing. 2003; 12(17): 1038-1042. PMid: 14512860. https://doi.org/10.12968/bjon.2003.12. 17.11719

[9] Ganz FD, Kaufman N, Israel S, et al. Resuscitation in general medical wards: who decides? Journal of Clinical Nursing. 2013; 22: 848-855. PMid: 23186542. https ://doi.org/10.1111/j.1365 $-2702.2012 .04240 . x$

[10] Al Khalaileh M. Jordanian critical care nurses' attitudes toward and experiences of do not resuscitate orders. International Jour- nal of Palliative Nursing. 2014; 20(8): 403-408. PMid: 25151868. https://doi.org/10.12968/ijpn.2014.20.8.403

[11] SIAARTI. Le cure di fine vita e l'Anestesista-Rianimatore: Raccomandazioni SIAARTI per l'approccio al malato morente-Update 2018. SIAARTI. 2018; 1-50.

[12] Forum: la legge n. 219 del 2017 Norme in materia di consenso informato e di disposizioni anticipate di trattamento. BioLaw Journal. 2018. Available from: www.biodiritto.org

[13] Goniewicz M, Rzonca P, Klukow J, et al. DNR declaration-emergency medical system nurses' opinions. Central European Journal of Medicine. 2013; 8(1): 69-74. https ://doi.org/10.2478/s115 36-012-0092-y

[14] Thibault-Prevost J, Jensen LA, Hodgins M. Critical Care Nurses Perceptions of DNR Status. Journal of Nursing Scholarship. 2000; 32(3): 259-265. PMid: 12462820. https ://doi.org/10.1111/j . 1547-5069.2000.00259.x

[15] Naess M. "Do-Not-Attempt-Resuscitation"-order in ICCUs: A survey of attitudes and experiences of nurses in Norway. Intensive and Critical Care Nursing. 2009; 25: 140-146. PMid: 18573661. https://doi.org/10.1016/j.iccn.2008.05.001

[16] Thibault-Prevost J, Jensen LA, Hodgins M. Critical Care Nurses Perceptions of DNR Status. Journal of Nursing Scholarship. 2000; 32(3): 259-265. PMid: 12462820. https ://doi.org/10.1111/j . 1547-5069.2000.00259.x

[17] Petrini M. La cura della persona anziana morente. Oikonomia. 2014 Available from: http://www.oikonomia.it/index.php/it/ 2014-05-31-23-52-11/ottobre-2014/342-la-cura-del la-persona-anziana-morente

[18] Detering K, Hancock A, Reade M, et al. The impact of advance care planning on end of life care in elderly patients: Randomised controlled trial. British Medical Journal. 2010; 340: 1345. PMid: 20332506. https://doi.org/10.1136/bmj.c1345

[19] Sudore R, Fried T. Redefining the "planning" in advance care planning: Preparing for end-of-life decision making. Annals of Internal Medicine. 2010; 153: 256. PMid: 20713793. https ://doi.org/ 10.7326/0003-4819-153-4-201008170-00008 